\title{
AXIAL MECHANICAL PROPERTIES OF \\ SMALL-DIAMETER ROUND TIMBER SHORT COLUMNS AFTER EXPOSURE TO ELEVATED TEMPERATURES
}

\author{
Kang He, Yu Chen, Jiayu Sun \\ Fuzhou University \\ Fuzhou, China \\ (Received January 2020)
}

\begin{abstract}
A total of forty-eight specimens were tested, including forty short timber columns at elevated temperatures and eight short timber columns left untreated at ambient temperature. The main parameters explored in the test include column heights (135, 180, 225 and $270 \mathrm{~mm}$ ), elevated temperature duration $(10,20,30,40$ and $50 \mathrm{~min})$ and section form. It was found that two new failure modes were generated after the specimens exposed to the elevated temperatures: splitting failure and bottom crushing, and the ultimate bearing capacity of the specimens with bottom crushing is the lowest. The ductility of circular specimens increases with the increases of column height. When the elevated temperature duration reaches $50 \mathrm{~min}$, the plasticity of the specimens basically subside. The ultimate bearing capacity of the timber columns decreases with the increase of the elevated temperature duration and the maximum reduction is about $60 \%$ percent.
\end{abstract}

KEYWORDS: Small-diameter round timber, elevated temperature, column height, ultimate bearing capacity, axial compression.

\section{INTRODUCTION}

Wood is a renewable green building material that consumes far less energy and carbon emissions over its lifetime than concrete, masonry and steel structures, and wood structure is a kind of green building with broad application prospect (Yang et al. 2003). Small-diameter round timber generally refers to small trees, shrubs, immature large trees, the tip part of large diameter conifer and broad-leaved trees with a diameter of 40-160 mm (Wolfe et al. 2005). The trail wood mainly comes from the thinning operation during the plantation tending period, and the yield is very high. If the by-product of the forest is utilized to build the wood structure, the economic value of the trail wood can be increased and the construction cost of the wood structure can be reduced. The research on small-diameter round timber mainly focuses on its materiality 
and connection method. Shim et al. (2009) proposed a nail-steel connection suitable for smalldiameter round timber, which can be used as tension and compression rods for trusses or space structures. Boren et al. (2000) tested the ultimate compression strength parallel to grain, bending strength and bending stiffness of the small-diameter round timber. Voth et al. (2015) discussed the development of a thin-walled wood-strand 3D core element that showed promise for a variety of panelized construction applications. Ferndndez-Golfin et al. (2007) tested the bending strength and elastic modulus of small diameter Laricio pine with diameter of 80-140 mm. Wolfe et al. (2000a,b) tested the ultimate compression strength parallel to grain and flexural strength of three kinds of small diameter and mature wood (Pinus ponderosa, Pseudotsuga menziesii and Abies concolor), and the results showed that there was no significant difference between the flexural strength value of small diameter wood and that of mature wood, while the compressive strength was lower than that of mature wood.

Many scholars have studied fire resistance and compression mechanical properties of wood members. Pering et al. (1980) measured the variation of the ultimate tensile strength and mass weight of the red wood, and the relationship between the ultimate tensile strength and the quality loss was established. Zeeland et al. (2005) studied the compressive behavior of wood at high temperatures. The stability and behaviour of the deflection wood columns under loading in buckling have been tested by Kudela et al. (2005). An experiment for the calculation of the fire resistance of timber beams and columns was investigated by Lie et al. (1977), which presented some simple formulas for calculating fire resistance of timber beams and columns. Compression mechanical properties of wood at temperatures simulating fire conditions had been obtained by Young et al. (2001). Ali et al. (2006) investigated the fire resistance of heavy wood columns taking into account the effect of two structural factors. Some brief statistics were presented on fatal fires in Swedish one-family houses, which indicating that the risk of fatality was not higher in wood houses than in a house built of noncombustible material by Kai (1985). The effect of thermal treatment of Norway spruce wood on its fire risk and mechanical properties was studied by Kloiber et al. (2010) and Martinka et al. (2013). Richardson et al. (2015) studied fire resistance of wood decking for heavy wood constructions. Reviewing fire resistance tests of wood slabs under natural fire conditions, the study explained why effective conductivity values, ISO 834 standard fire scenario by given correct results by Konig et al. (2006). Moya et al. (2017) evaluated the durability in terms of decay and mechanical resistance of thermally modified wood of Tectona grandis and Gmelina arborea treated at 160, 180, 200 and $220^{\circ} \mathrm{C}$. Noel et al. (2014) studied the viscoelastic properties and mechanical performance of wood modified by biopolyester treatments. Cetera et al. (2016) examined the mechanical properties of Turkey oak wood before and after combined steam and thermal treatments under vacuum conditions. The variation in the charring depth of wood studs inside wood-frame walls in a fire was investigated by Su et al. (2019). Zicherman et al. (1982) introduced differences in microstructural detail between wood and char, as well as fissure geometry. Structural fire design according to Eurocode 5-design rules were presented by Konig et al. (2005). Zeeland et al. (2005) established a model to predict the residual strength in compression parallel to grain for dimension wood subjected to axial loads at elevated temperatures. Janssens et al. (2004) conducted a model of the thermal degradation of structural wood members after being subjected to fire.

In this review, there are few research on fire resistance and post-fire performance of smalldiameter round timbered structures. In addition, the mechanical properties of the small-diameter round timber as a bearing column after exposure to high temperature are not clear, which also limits the application of small-diameter round timber in wood structure to some extent. In this paper, through high temperature test and axial pressure test, axial mechanical properties of smalldiameter round timber short columns after exposure to elevated temperatures are studied. 


\section{MATERIAL AND METHODS}

\section{Test specimens}

Small-diameter round timber of Larix gmelini have been used in this test, and the tree ages of Larix gmelini were between 13 and 17 age gradations. Forty-eight wood short columns with different column heights $(135,180,225$ and $270 \mathrm{~mm})$ are prepared and forty specimens were exposed to elevated temperatures. In order to eliminate the influence of instability on the specimen, the slenderness ratio of the short columns was controlled to be no more than three, and the maximum height of the corresponding specimen was $270 \mathrm{~mm}$. The other main parameter was the elevated temperature duration, including 0, 10, 20, 30, 40 and $50 \mathrm{~min}$. And the elevated temperature duration of $0 \mathrm{~min}$ was used to represent the specimens that have not undergone elevated temperature treatment.

\section{Physical parameters of wood}

Considering the large variability of the physical parameters of the small-diameter round timber, sufficient test samples were selected for statistical analysis. Indexes such as moisture content, air-dry density, the ultimate compression strength parallel to grain and elasticity modulus were tested respectively. Sample size, specimen size and test results are shown in Tab. 1.

Tab.1: Test results of physical parameters.

\begin{tabular}{|l|c|c|c|c|}
\hline \multicolumn{1}{|c|}{ Physical parameters } & Average value & $\begin{array}{c}\text { Coefficient } \\
\text { of variation (\%) }\end{array}$ & $\begin{array}{c}\text { Specimen size } \\
\text { (chordwise, radial, } \\
\text { longitudinal) }\end{array}$ & Sample size \\
\hline Moisture content & $11.8 \%$ & 2.3 & $20 \times 20 \times 20 \mathrm{~mm}$ & 25 \\
\hline Air-dry density & $0.474 \mathrm{~g} \cdot \mathrm{cm}^{-3}$ & 15.2 & $20 \times 20 \times 20 \mathrm{~mm}$ & 25 \\
\hline $\begin{array}{l}\text { Ultimate compression } \\
\text { strength parallel to grain }\end{array}$ & $18.0 \mathrm{MPa}$ & 17.1 & $20 \times 20 \times 20 \mathrm{~mm}$ & 35 \\
\hline Elasticity modulus & $9638 \mathrm{MPa}$ & 19.4 & $20 \times 20 \times 20 \mathrm{~mm}$ & 35 \\
\hline
\end{tabular}

\section{Heating procedures}

The elevated temperature test was realized by the intelligent temperature control resistance fire furnace. The temperature control in the furnace during the heating phase referred to the ISO-834 standard heating curve (Moss et al. 2008) and the specific temperature equation is shown in Eq. (1):

$$
T=T_{0}+345 \lg (8 t+1)
$$

where: $T_{0}\left({ }^{\circ} \mathrm{C}\right)$ - the initial temperature in the test furnace, and $T\left({ }^{\circ} \mathrm{C}\right)$ is the average temperature in the test furnace after the heating time $t$ (min).

The critical carbonization temperature of wood is usually between $260^{\circ} \mathrm{C}$ and $330^{\circ} \mathrm{C}$. In order to let the test wood column enter the carbonization stage and avoid flashover, the maximum temperature of this elevated temperature test was set at $400^{\circ} \mathrm{C}$. To study the influence of elevated temperature duration on the mechanical properties of the specimens, five grades of elevated temperature duration of 10-50 min were set. And the duration of high temperature was calculated from the furnace temperature up to $400^{\circ} \mathrm{C}$. When the high temperature treatment reached the specified duration, the electric furnace stopped heating and opened the door. The furnace used 
in this test is a closed fire furnace without ventilation. Therefore, in order to avoid the convection generated by the opening of the furnace door to cause secondary combustion of the wood column, after the door of the furnace was opened, the specimen was quickly immersed in water and cooled for three minutes. The column was then removed from the water and placed in an outdoor ventilated environment for 48 hours to ensure that the column was fully dried. Then the pressure test of the column was conducted.

\section{Loading procedures}

All specimens were tested with the electro-hydraulic servo universal testing machine with the ultimate capacity of $1000 \mathrm{kN}$. The specimens were first placed on a support. In order to ensure pure axial compression, the bottom plate was adjusted to be parallel to the top plate. The axial pressure test was step by step load, and each load was maintained for 2 to $3 \mathrm{~min}$. When the specimen was in the elastic range, the load of each stage was $10 \%$ of the estimated ultimate load. When the load exceeded $40 \%$ of the estimated load, $5 \%$ of the estimated ultimate load was taken for each stage. The peak load obtained in the compression test was defined as the ultimate bearing capacity $\left(N_{u}\right)$ of wood short columns.

\section{RESULTS AND DISCUSSION}

\section{Failure modes}

The axial pressure test yielded three different failure modes, shear failure (SF), splitting failure (SPF) and bottom crushing (BC), as shown in Fig. 1. The failure phenomena of square short wood column and circular short wood column in axial pressure test are basically the same. In Fig. 1 the photo on the left is the circular column, and the square column is on the right.

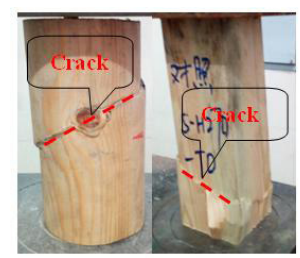

(a) Shear failure (SF)

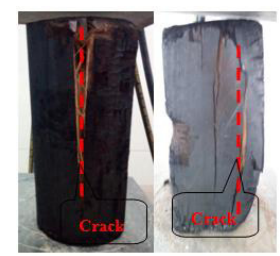

(b) Splitting failure (SPF)

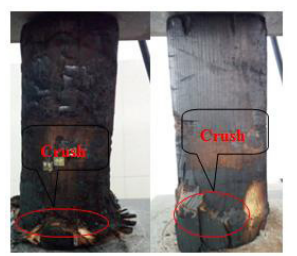

(c) Bottom crushing (BC)

Fig. 1: Typical failure modes of specimens.

After the test was completed, both the ultimate bearing capacity and failure modes of all specimens were recorded. Details of failure modes were shown in Tab. 2.

Tab. 2: Experimental results for all specimens.

\begin{tabular}{|l|c|c|c|c|c|c|c|}
\hline Specimen label & $\begin{array}{c}N_{\mathrm{u}} \\
(\mathrm{kN})\end{array}$ & $\begin{array}{c}P e r \\
(\%)\end{array}$ & $\begin{array}{c}K \\
\left(\mathrm{kN} \cdot \mathrm{mm}^{-1}\right)\end{array}$ & $\begin{array}{c}\Delta_{y} \\
(\mathrm{~mm})\end{array}$ & $\begin{array}{c}\Delta_{u} \\
(\mathrm{~mm})\end{array}$ & $\Delta_{u} / \Delta_{y}$ & $\begin{array}{c}\text { Failure } \\
\text { modes }\end{array}$ \\
\hline CH135T0 & 143.75 & 0 & 52.87 & 3.79 & 5.13 & 1.35 & $\mathrm{SF}$ \\
\hline CH135T10 & 138.60 & 3.5 & 26.41 & 5.60 & 7.57 & 1.35 & $\mathrm{SPF}$ \\
\hline CH135T20 & 103.10 & 29.1 & 23.99 & 4.97 & 6.75 & 1.36 & $\mathrm{SPF}$ \\
\hline CH135T30 & 88.25 & 38.6 & 10.11 & 6.86 & 10.88 & 1.59 & $\mathrm{SPF}$ \\
\hline
\end{tabular}


Vol. 65 (6): 2020

\begin{tabular}{|c|c|c|c|c|c|c|c|}
\hline CH135T40 & 63.00 & 56.7 & 12.11 & 5.03 & 7.28 & 1.45 & $\mathrm{BC}$ \\
\hline CH135T50 & 51.55 & 67.6 & 3.94 & 11.06 & 15.3 & 1.38 & $\mathrm{BC}$ \\
\hline CH180T0 & 126.15 & 0 & 47.68 & 2.86 & 3.96 & 1.38 & SF \\
\hline CH180T10 & 100.60 & 20.1 & 32.12 & 3.15 & 4.83 & 1.53 & SPF \\
\hline CH180T20 & 90.65 & 28 & 25.63 & 3.81 & 5.85 & 1.54 & $\mathrm{SPF}$ \\
\hline CH180T30 & 104.70 & 16.7 & 7.25 & 11.64 & 15.15 & 1.30 & SPF \\
\hline CH180T40 & 91.15 & 27.6 & 10.43 & 7.96 & 11.28 & 1.42 & $\mathrm{SPF}$ \\
\hline CH180T50 & 46.85 & 54.9 & 3.39 & 13.45 & 18.24 & 1.36 & $\mathrm{BC}$ \\
\hline $\mathrm{CH} 225 \mathrm{~T} 0$ & 167.40 & 0 & 38.18 & 3.55 & 5.96 & 1.68 & SF \\
\hline $\mathrm{CH} 225 \mathrm{~T} 10$ & 115.95 & 30.4 & 33.46 & 3.96 & 10.56 & 2.67 & SPF \\
\hline $\mathrm{CH} 225 \mathrm{~T} 20$ & 111.55 & 33.3 & 29.28 & 4.80 & 12.98 & 2.70 & SPF \\
\hline CH225T30 & 91.05 & 29.2 & 10.67 & 7.17 & 14.91 & 2.08 & SPF \\
\hline $\mathrm{CH} 225 \mathrm{~T} 40$ & 95.30 & 37.7 & 9.08 & 9.03 & 12.94 & 1.43 & SPF \\
\hline $\mathrm{CH} 225 \mathrm{~T} 50$ & 48.10 & 66.9 & 2.45 & 17.45 & 25.34 & 1.45 & SPF \\
\hline CH270T0 & 139.30 & 0 & 26.48 & 4.35 & 6.21 & 1.43 & $\mathrm{SF}$ \\
\hline $\mathrm{CH} 270 \mathrm{~T} 10$ & 116.85 & 20.3 & 24.97 & 6.84 & 39.15 & 5.72 & SPF \\
\hline $\mathrm{CH} 270 \mathrm{~T} 20$ & 143.65 & -3.1 & 24.76 & 9.26 & 26.03 & 2.81 & SPF \\
\hline CH270T30 & 129.70 & 2.7 & 16.46 & 7.87 & 20.04 & 2.55 & SPF \\
\hline $\mathrm{CH} 270 \mathrm{~T} 40$ & 109.90 & 10.9 & 15.82 & 11.12 & 32.47 & 2.92 & $\mathrm{SF}$ \\
\hline $\mathrm{CH} 270 \mathrm{~T} 50$ & 72.40 & 47.2 & 3.86 & 14.23 & 21.97 & 1.54 & SPF \\
\hline SH135T0 & 170.20 & 0 & 53.53 & 3.55 & 4.95 & 1.39 & $\mathrm{SF}$ \\
\hline SH135T10 & 158.80 & 6.7 & 48.43 & 4.42 & 10.57 & 2.39 & SF \\
\hline SH135T20 & 109.40 & 21.6 & 29.98 & 4.51 & 5.25 & 1.16 & SPF \\
\hline SH135T30 & 92.30 & 48.8 & 9.92 & 9.20 & 16.3 & 1.77 & SPF \\
\hline SH135T40 & 62.50 & 54.4 & 9.11 & 8.54 & 14.21 & 1.66 & $\mathrm{BC}$ \\
\hline SH135T50 & 50.05 & 71.1 & 4.67 & 8.22 & 15.84 & 1.93 & $\mathrm{BC}$ \\
\hline SH180T0 & 141.65 & 0 & 42.77 & 4.69 & 6.52 & 1.39 & SF \\
\hline SH180T10 & 146.95 & -3.9 & 41.31 & 4.14 & 6.46 & 1.56 & SF \\
\hline SH180T20 & 116.45 & 18.3 & 23.73 & 12.60 & 19.15 & 1.52 & SPF \\
\hline SH180T30 & 64.55 & 54.4 & 9.48 & 6.51 & 13.08 & 2.01 & SPF \\
\hline SH180T40 & 75.65 & 46.6 & 12.62 & 7.85 & 14.76 & 1.88 & SPF \\
\hline SH180T50 & 48.45 & 60.2 & 4.32 & 10.31 & 20 & 1.94 & $\mathrm{BC}$ \\
\hline SH225T0 & 139.45 & 0 & 33.96 & 5.54 & 11.67 & 2.11 & $\mathrm{SF}$ \\
\hline SH225T10 & 107.30 & 23.2 & 35.82 & 4.44 & 8.19 & 1.84 & SPF \\
\hline SH225T20 & 89.75 & 34.3 & 20.59 & 5.45 & 8.73 & 1.60 & SPF \\
\hline SH225T30 & 69.55 & 42.2 & 9.02 & 6.73 & 9.46 & 1.41 & $\mathrm{BC}$ \\
\hline SH225T40 & 59.75 & 46.6 & 8.76 & 6.75 & 9.41 & 1.39 & SPF \\
\hline SH225T50 & 56.25 & 47.5 & 5.93 & 12.13 & 24.58 & 2.03 & SPF \\
\hline SH270T0 & 149.95 & 0 & 37.16 & 5.23 & 7.2 & 1.38 & $\mathrm{SF}$ \\
\hline SH270T10 & 120.20 & 23.7 & 27.15 & 6.35 & 16.51 & 2.60 & SPF \\
\hline SH270T20 & 109.75 & 27.1 & 27.14 & 5.38 & 7.1 & 1.32 & SPF \\
\hline SH270T30 & 114.20 & 34.9 & 12.37 & 20.05 & 48.54 & 2.42 & SPF \\
\hline SH270T40 & 54.3 & 65.5 & 7.56 & 7.65 & 12.19 & 1.59 & $\mathrm{BC}$ \\
\hline SH270T50 & 73.15 & 44.5 & 6.00 & 11.24 & 30.25 & 2.69 & SPF \\
\hline
\end{tabular}

Note $(\mathrm{SF}=$ Shear failure, $\mathrm{SPF}=$ Splitting failure, $\mathrm{BC}=$ Bottom crushing). 
Fig. 1a showed shear failure (SF), it can be seen that diagonal crack occurred near the midheight of the circular wood columns, and diagonal crack occurred near the bottom of square wood columns. As can be seen from Tab. 2, 11 wood columns failed with shear failure (SF). All specimens not subjected to high temperature treatment $(T=0 \mathrm{~min})$ failed with shear failure (SF). From Fig. 1b, cracks first occurred at the top of wood columns. With the increase of load, splitting failure (SPF) was observed during the experiments. As can be seen from Tab. 2, 29 wood columns that failed with splitting failure (SPF) were mainly the specimens with the column height of $270 \mathrm{~mm}$ and $225 \mathrm{~mm}$. And the number of specimens with splitting failure accounted for $72.5 \%$ of the total number of specimens exposed to high temperatures. Bottom crushing (BC) was observed at the bottom place, accompanied with severe carbonization, as shown in Fig. 1c. From Tab. 2, 8 specimens that failed with bottom crushing (BC) were mainly the specimens with the elevated temperature duration of $40 \mathrm{~min}$ and $50 \mathrm{~min}$. Except for the specimens SH270T40 and SH225T30, the remaining 6 specimens that failed with bottom crushing all correspond to the smaller slenderness ratio, and the column height of them are $135 \mathrm{~mm}$ or $180 \mathrm{~mm}$. The ultimate bearing capacity of specimens with bottom crushing was significantly lower than that of other specimens, and the ultimate bearing capacity of them was never exceeds $100 \mathrm{kN}$. In brief, without high temperature effect of the wood short column shear failure (SF) occurred. The failure mode of wood short column was changed after exposure to elevated temperatures, which was mainly splitting failure (SPF).

\section{Displacement response}

The relationship between load $(P)$ and displacement $(\Delta)$ of specimens with same elevated temperature duration and different column heights are shown in Fig. 2 and Fig. 3, in which the horizontal coordinate-axis $\Delta$ represents the axial displacement and the vertical coordinate-axis $P$ represents the axial compression load.

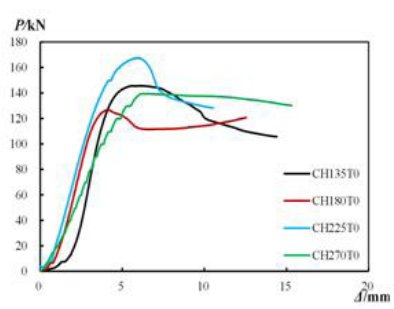

(a) $\mathrm{T}=0$ min.

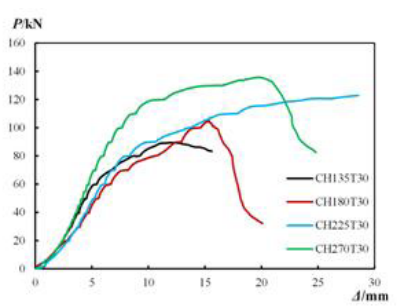

(b) $\mathrm{T}=30 \mathrm{~min}$.

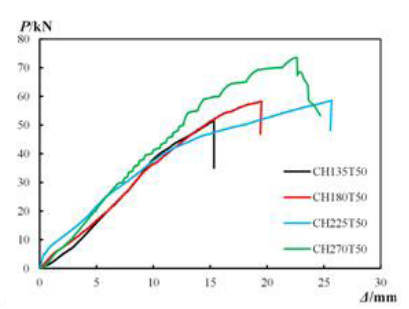

(c) $\mathrm{T}=50 \mathrm{~min}$.

Fig. 2: Load versus displacement curves for circular specimens with different column height.

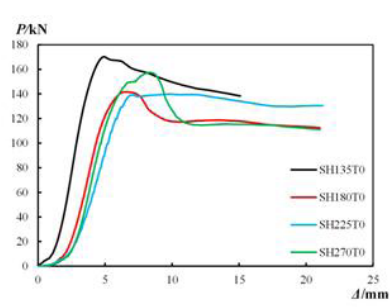

(a) $\mathrm{T}=0$ min.

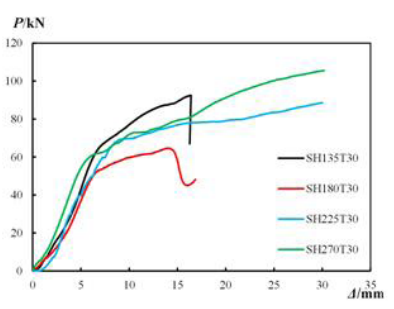

(b) $\mathrm{T}=30 \mathrm{~min}$.

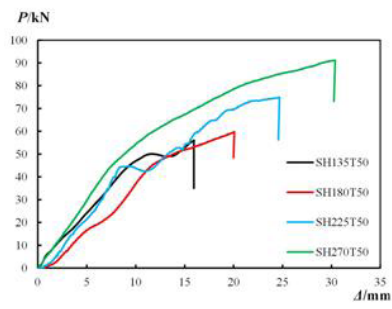

(c) $\mathrm{T}=50 \mathrm{~min}$.

Fig. 3: Load versus displacement curves for square specimens with different column height. 
It can be seen that the load displacement curves of wood columns contain three stages: elastic stage, elastic-plastic stage and descent stage. For the specimens with elevated temperature duration of $50 \mathrm{~min}$, the curve only contains the elastic stage and the descent stage.

In Tab. 2, $\mathrm{K}$ is the initial stiffness defined as the slope of the load displacement curve in the elastic stage. Initial stiffness at the elastic stage is the resistance of a body at the elastic stage to deformation by an applied force, and can be expressed as $K=\mathrm{P} / \Delta$. In the paper, the axial load $\mathrm{P}$ was selected as $40 \%$ of the recorded ultimate load $\left(N_{\imath}\right)$. The ductility of specimens is evaluated by the ductility coefficient $\left(\Delta_{z} / \Delta_{y}\right)$.The yield displacement $\left(\Delta_{y}\right)$ was obtained by using secant of the axial load vs. vertical deformation curve passing through the point at which the axial load reaches $75 \%$ of the ultimate load $\left(0.75 N_{u}\right)$. The ultimate displacement $\left(\Delta_{u}\right)$ corresponds to the ultimate load $\left(N_{u}\right)$ on the load versus displacement curve. From Fig. 2 and Tab. 2, the initial stiffness of circular wood columns with the same elevated temperature duration and different column heights is basically similar. It is shown that column height has little effect on the initial stiffness of the post-heated specimens. As shown in Tab. 2, for the circular wood column, it can be found that when the column height increases from $135 \mathrm{~mm}$ to $270 \mathrm{~mm}$, the ductility coefficient $\left(\Delta_{\imath} / \Delta_{y}\right)$ of the specimen increases significantly. But this rule was not found in the square column. The results demonstrate that the ductility of circular wood columns increases with the increases of column height. And the higher the elevated temperature duration of circular wood columns is, the smaller the ultimate bearing capacity $\left(N_{\psi}\right)$ of circular wood columns shows. The results demonstrate that elevated temperature duration investigated here has a great influence on the ultimate bearing capacity of specimens, which can also be found in the square wood columns.

\section{Effect of elevated temperature duration}

As can be seen from Fig. 4, Fig. 5a and Tab. 2, elevated temperature duration have negative influence on the ultimate bearing capacity of circular wood columns after exposure to elevated temperatures.

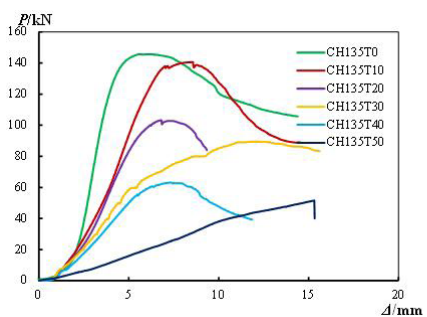

(a) $\mathrm{H}=135 \mathrm{~mm}$.

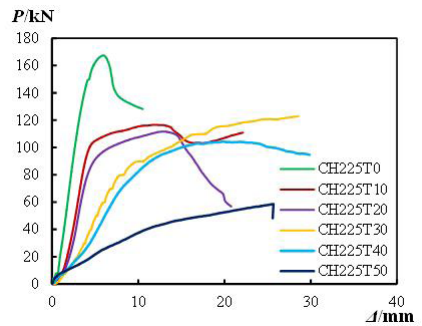

(c) $\mathrm{H}=225 \mathrm{~mm}$.

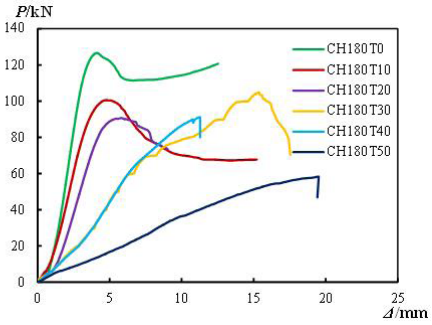

(b) $\mathrm{H}=180 \mathrm{~mm}$.

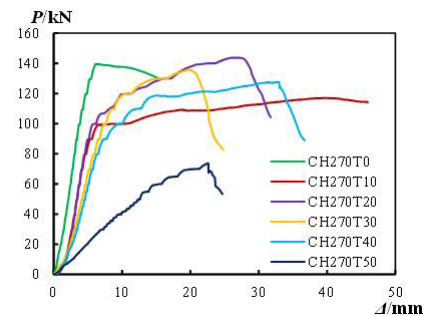

(d) $\mathrm{H}=270 \mathrm{~mm}$.

Fig. 4: Load versus displacement curves for circular specimens with different elevated temperature duration. 
As shown in Fig. 4, compared with other specimens, the ultimate bearing capacity of the specimens with elevated temperature duration of 50 min decreased the most.

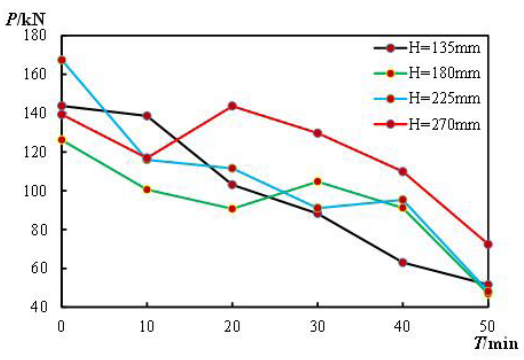

(a) P-T curve of circular wood columns.

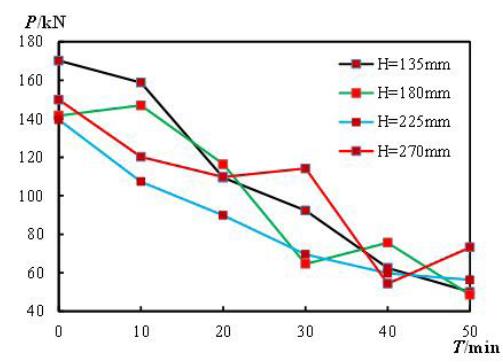

(b) P-T curve of square wood columns.

Fig. 5: P-T curves.

As shown in Fig. 5a, with the increase of elevated temperature duration, the ultimate bearing capacity of circular wood columns decreases. In Tab. 2, the percentage decline in ultimate capacity (Per) is used to represent the decreasing proportion of the ultimate bearing capacity of the specimen after high temperature treatment. For specimens with the column height $135 \mathrm{~mm}$, after being exposed to various elevated temperature duration levels of 10, 20,30, 40, and $50 \mathrm{~min}$, the experimental ultimate bearing capacity has an distinctive reduction of $3.5 \%, 29.1 \%, 38.6 \%$, $56.7 \%$ and $67.6 \%$ respectively, compared with that of specimens without being exposed to elevated temperature (CH135T0).

It can be seen from the Fig. $5 \mathrm{~b}$ that the ultimate bearing capacity of square wood columns decreases with the increase of elevated temperature duration when the column heights are $135 \mathrm{~mm}$ and $225 \mathrm{~mm}$. For the columns with the height of $180 \mathrm{~mm}$ and $270 \mathrm{~mm}$ respectively, with the increase of the duration of elevated temperature, the ultimate bearing capacity of the specimens did not always decrease, but fluctuated. But the overall trend of the ultimate bearing capacity decreases with the increase of elevated temperature duration. Compared with the specimens without being subjected to elevated temperatures $(T=0 \mathrm{~min})$, the residual bearing capacity decreased as the elevated temperature duration increase. As can be seen from Tab. 2, when the column height is $135 \mathrm{~mm}$, the percentage loss in ultimate bearing capacity increases from $0.0 \%$ to $71.1 \%$ as the elevated temperature duration increased from $0 \mathrm{~min}$ to $50 \mathrm{~min}$.

\section{Effect of column height}

Fig. 6 and Tab. 2 shows the effect of column height on ultimate bearing capacity of specimens.

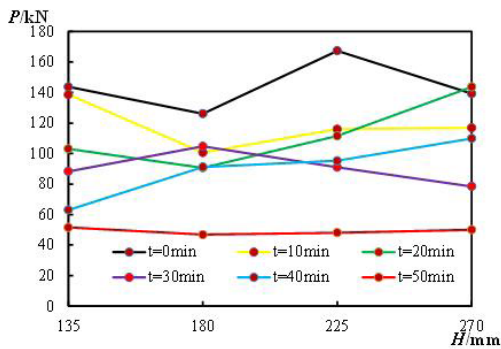

(a) P-H curve of circular wood columns.

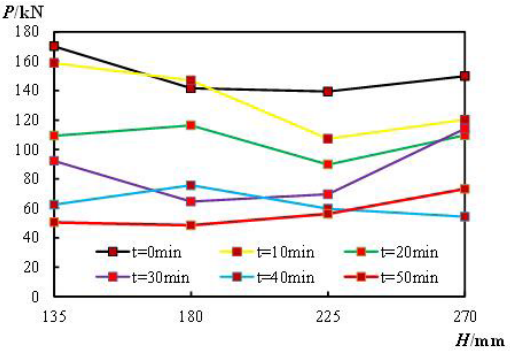

(b) P-H curve of square wood columns.

Fig. 6: $P-H$ curves. 
It can be found that there is no obvious upward or downward tendency with the increase of column height for specimen with 50 min elevated temperature duration, as seen in Fig. 6a, which indicates that column height has slight influence on the ultimate bearing capacity for specimens with 50 min elevated temperature duration. It can be seen from Fig. 6a, when the elevated temperature duration are $20 \mathrm{~min}$ and $40 \mathrm{~min}$, the ultimate bearing capacity of circular wood columns increases with the increase of the column height. When the elevated temperature duration are $0 \mathrm{~min}$ and $10 \mathrm{~min}$, the ultimate bearing capacity of circular wood column decreases first and then increases with the increase of column height. As can be seen from Tab. 2, for circular wood columns, when the elevated temperature duration are $10 \mathrm{~min}, 20 \mathrm{~min}, 40 \mathrm{~min}$ and $50 \mathrm{~min}$, the ductility of specimens increase with the increase of column height. When the elevated temperature duration is $0 \mathrm{~min}$ and $30 \mathrm{~min}$, the ductility of specimen increase first and then decrease. Overall, column height can improve the ductility of circular wood column slightly.

As can be seen from Fig. 6b, when the elevated temperature duration are 0, 10, and $30 \mathrm{~min}$, the ultimate bearing capacity of square wood columns decreases first and then increases with the increase of column height. It can be found that the lines have some fluctuations, but the upward or downward tendency is not obvious with the increase of column height. When the elevated temperature duration is $40 \mathrm{~min}$, the ultimate load-bearing capacity of the square wood column increases first and decreases then with the increase of column height. When the elevated temperature duration is $50 \mathrm{~min}$, the ultimate bearing capacity of the column increased slightly. Overall, column height has slight influence on the ultimate bearing capacity for square wood columns.

\section{Parameter formulas}

Based on the above results verifications and parameter analysis, it can be found that ultimate bearing capacity of the wood columns after being exposed to elevated temperatures is determined by the reduction coefficient $K_{r}$, which is mainly affected by the elevated temperature duration and the column height. The ultimate bearing capacity of specimens after exposure to elevated temperatures $N_{c u}$ is given by following Eq. 2:

$$
N_{c u}=K_{r} \times N_{O}
$$

In which, $N_{O}$ is the calculated ultimate bearing capacity of circular wood columns and square wood columns without being exposed to elevated temperatures. The value of $N_{O}$ in Eq. 2 can be determined by using the following Eq. 3:

$$
N_{O}=f_{c} \times A_{s}
$$

where, $A_{s}$ is the cross-sectional area of circular wood columns or square wood columns, $f_{c}$ is the ultimate compression strength parallel to grain in Tab. 1 .

Based on the above equations, the calculated ultimate bearing capacity of circular wood columns and square wood columns without being exposed to elevated temperatures are $127.5 \mathrm{kN}$ and $145.8 \mathrm{kN}$ resp. To simplify the calculation, $\alpha$ and $\beta$ are quoted, and the $\mathrm{Kr}$ are calculated by the Eq. (4). The definition of $\alpha$ is given by Eq. (5), $\beta$ is given by Eq. (6):

$$
\begin{aligned}
K_{r} & =f(\alpha) \times f(\beta) \\
\alpha & =\frac{H}{H_{0}}
\end{aligned}
$$




$$
\beta=\frac{1.2 \beta_{\mathrm{n}}}{T^{0.187}}
$$

where $\beta$ is effective char rate adjusted for elevated temperature duration $T$, $T$ represents elevated temperature duration, $\beta_{n}$ is nominal char rate. Refer to the research results of White et al. (1992), nominal char rate is $0.635 \mathrm{~mm} \cdot \mathrm{min}^{-1}$.

Based on the experimental dates, the calculated formula of $f(\alpha)$ and $f(\beta)$ are received by using IBM SPSS Statistics software for circular wood columns. Equations are received as follows:

$$
\begin{aligned}
& f(\alpha)=1.360-1.139 \times \alpha+0.426 \times \alpha^{2} \\
& f(\beta)=0.098 \times e^{4.700 \times \beta}
\end{aligned}
$$

Based on the experimental dates, the calculated formula of $f(\alpha)$ and $f(\beta)$ are received by using IBM SPSS Statistics software for square wood columns. Equations are received as follows:

$$
\begin{aligned}
& f(\alpha)=1.382-1.158 \times \alpha+0.369 \times \alpha^{2} \\
& f(\beta)=0.035 \times e^{6.738 \times \beta}
\end{aligned}
$$

In order to verify the accuracy of the formulas, the ultimate bearing capacity of specimens after exposure to elevated temperatures calculated by the formulas is compared with that from the test. $N_{c u}$ is the ultimate bearing capacity of specimens after exposure to elevated temperatures calculated by the formulas, and $N_{u}$ is the ultimate bearing capacity of specimens after exposure to elevated temperatures from the test. In the Fig. 7, which can be seen all of the value of $N_{c u} / N_{u}$ ranges from 0.60 to 1.20 , and the value is quite close to 1.00 . The formulas are proved to be reasonable and conservative.
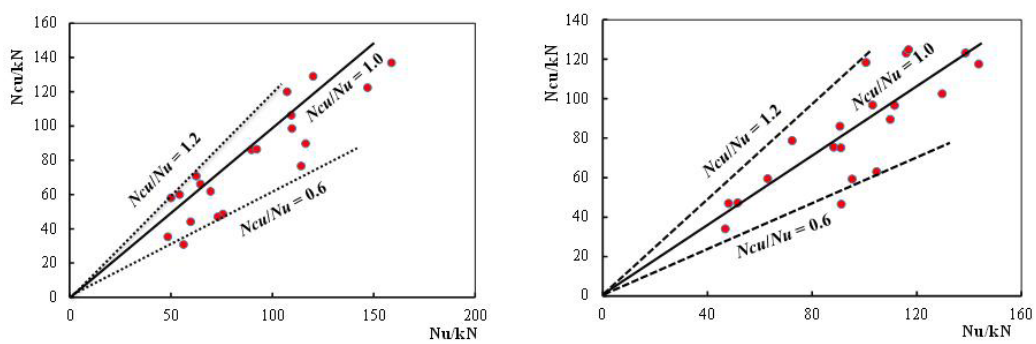

(a) Square specimens.

(b) Circular specimens.

Fig. 7: Distribution of the $\mathrm{Ncu} / \mathrm{Nu}$.

\section{CONCLUSIONS}

The shear failure mode of short timber columns under axial pressure was changed by elevated temperature treatment, and two new failure modes were generated: splitting failure and bottom crushing. Among the three failure modes, the ultimate bearing capacity of the specimens with bottom crushing is the lowest. There is a difference in the influence of column height on the ductility of square and circular short timber columns after exposure to elevated temperatures. The ductility of circular specimens increases with the increases of column height, but the law was not 
found in the square specimens. And the initial stiffness of the timber columns decreases with the increase of the elevated temperature duration.

The load displacement curves of most short timber columns contain three stages: elastic stage, elastic-plastic stage and descent stage. But for the specimens with elevated temperature duration of $50 \mathrm{~min}$, the curves only contain the elastic stage and the descent stage and the plasticity of the specimens basically subside. The ultimate bearing capacity of the short timber columns decreases with the increase of the elevated temperature duration. When the elevated temperature duration reaches $50 \mathrm{~min}$, the maximum reduction of the ultimate bearing capacity of the specimens is about sixty percent.

\section{ACKNOWLEDGMENTS}

This research work was supported by the National Natural Science Foundation of China (No. 51778066).

\section{REFERENCES}

1. Ali, F., Kavanagh, S., 2006: Fire resistance of timber columns. Journal of the Institute of Wood Science 17(2): 85-93.

2. Boren, H., Barnard, G., 2000: Analysis of the strength and stiffness properties for small diameter round Scots pine timber tested in bending and compression parallel to the grain. Paper and timber 82(1): 48-56.

3. Cetera, P., Todaro, L., Lovaglio, T., Moretti, N., Rita, A., 2016: Steaming treatment decreases MOE and compression strength of Turkey oak wood. Wood Research 61(2): 255-263.

4. Fernandez-Golfin, J.I., Diez-Barra, M.R., Hermoso, E., Mier, R., 2007: Mechanical characterization of visually classified, small-diameter Laricio pine round timber. Spanish Journal of Agricultural Research 5(3): 304-311.

5. Janssens, M.L., 2004: Modeling of the thermal degradation of structural wood members exposed to fire. Fire \& Materials 28(2-4):199-207.

6. Kudela, J., Slaninka, R., 2005: Stability of wood columns loaded in buckling. Part 3. Buckling of columns with initial deflection. Wood Research 50(4): 17-28.

7. Konig, J., 2005: Structural fire design according to Eurocode 5. Design rules and their background. Fire and Materials 29(3): 147-163.

8. Konig, J., 2006: Effective thermal actions and thermal properties of timber members in natural fires. Fire \& Materials 30(1): 51-63.

9. Kloiber, M., Frankl, J., Drdacky, M., Bryscejn, J., Tippner, J., Kucerova, I., 2010: Change of mechanical properties of Norway spruce wood due to degradation caused by fire retardants. Wood Research 55(4): 23-38.

10. Kai, O., 1985: Fire resistance of wood structures. Fire Technology 21(1): 34-40.

11. Lie, T.T., 1977: A method for assessing the fire resistance of laminated timber beams and columns. Canadian Journal of Civil Engineering 4(2): 161-169.

12. Martinka, J., Chrebet, T., Kral, J., Balog, K., 2013: An examination of the behaviour of thermally treated spruce wood under fire conditions. Wood Research 85(4): 599-605.

13. Moss, P.J., Dhakal, R.P., Wang, G., Buchanan, A.H., 2008: The fire behaviour of multibay, two-way reinforced concrete slabs. Engineering Structures 30(12): 3566-3573. 
14. Moya, R., Fallas-Valverde, L., Berrocal, A., Mendez-Alvarez, D., 2017: Durability of thermally modified wood of Gmelina arborea and Tectona grandis tested under field and accelerated conditions. Journal of Renewable Materials 5(3): 208-219.

15. Noel, M., Grigsby, W., Volkmer, T., 2014: Investigating the viscoelastic properties and mechanical performance of wood modified by biopolyester treatments. Journal of Renewable Materials 2(4): 291-305.

16. Pering, G.A., Springer, G.S., 1980: Decrease in tensile strength and in mass of burning wood. Fire Technology 16(4): 245-251.

17. Richardson, L.R., Batista, M., 2015: Fire resistance of timber decking for heavy timber construction. Fire \& Materials 25(1): 21-29.

18. Shim, K.B., Wolfe, R., Begel, M., 2009: Nailed mortised-plate connections for smalldiameter round timber. Wood and Fiber Science 41(3): 313-321.

19. Su, H.C., Tung, S.F., Tzeng, C.T., 2019: Variation in the charring depth of wood studs inside wood-frame walls with time in a fire. Wood Research 64(3): 449-459.

20. Voth, C., White, N., Yadama, V., Cofer, W., 2015: Design and evaluation of thin-walled hollow-core wood-strand sandwich panels. Journal of Renewable Materials 3(3): 234-243.

21. White, R.H., Nordheim, E.V., 1992: Charring rate of wood for ASTM E 119 exposure. Fire Technology 28(1): 5-30.

22. Wolfe, R., 2000: Research challenges for structural use of small-diameter round timbers. Forest Products Journal 50(2): 21-29.

23. Wolfe, R., Moseley, C., 2000: Small-diameter log evaluation for value-added structural applications. Forest Products Journal 50(10): 48-58.

24. Wolfe, R., Murphy, J., 2005: Strength of small-diameter round and tapered bending members. Forest Products Journal 55(3): 50-55.

25. Yang, H.S., Kim, D.J., Kim, H.J., 2003: Rice straw-wood particle composite for sound absorbing wooden construction materials. Bioresource Technology 86(2): 117-121.

26. Young, S.A., Clancy, P., 2001: Compression mechanical properties of wood at temperatures simulating fire conditions. Fire and Materials 25(3): 83-93.

27. Zeeland, I.M.V., Salinas, J.J., Mehaffey, J.R., 2005: Compressive strength of lumber at high temperatures. Fire \& Materials 29(2): 71-90.

28. Zeeland, I.M.V., Salinas, J.J., Mehaffey, J.R., 2005: Compressive streng th of lumber at high temperatures. Fire \& Materials 29(2): 71-90.

29. Zicherman, J.B., Williamson, R.B., 1982: Microstructure of wood char. Wood Science \& Technology 16(1): 19-34.

\author{
Kang He, Yu Chen*, Jiayu Sun \\ Fuzhou University \\ College of Civil Engineering \\ Fuzhou 35 OII6 \\ China
}

*Corresponding author: yuchen@fzu.edu.cn 